\title{
PENGEMBANGAN SPESIFIKASI TEKNIS \& PROTOTIPE SOFTWARE MULTIPLEKSER TV DIGITAL UNTUK SISTEM PERINGATAN DINI BENCANA (EWS) DI INDONESIA STUDI KASUS PEMANCAR TV DIGITAL DI LAB BPPT
}

\author{
Sofyan Mufti Prasetiyo \\ Program Studi Teknik Informatika, Universitas Pamulang \\ Jln. Surya Kencana No. 1 Pamulang, Tangerang Selatan \\ Email: dosen01809@unpam.ac,id
}

\begin{abstract}
ABSTRAK
Indonesia memiliki potensi terhadap bencana alam terutama tsunami dan gempa bumi. Pada siaran TV Digital terdapat konvergensi yakni adanya penggabungan antara Gambar, Suara dan Data, data dapat dimasukan informasi tentang bencana. Hal ini yang menjadi alasan pengiriman sinyal EWS dikirim melalui siaran TV Digital, Salah satu solusi yang feasible dalam hal ini yaitu dengan menumpang pada jaringan televisi. Dengan membandingkan teknis software multiplekser tv digital peringatan dini bencana pada beberapa standar televisi digital serta dengan melihat kebutuhan dasar sistem peringatan dini di Indonesia, penelitian ini mengajukan pengembangan spesifikasi teknis software multiplekser tv digital untuk sistem peringatan dini bencana (ews) di indonesia. Thesis ini juga membuat prototype dan skenario implementasi standar yang terdiri dari server bencana, server multipleks, dan set-top-box yang dilengkapi alert system. Dengan adanya spesifikasi teknis ini dapat meningkatkan percepatan pendistribusian informasi peringatan dini bencana ke masyarakat.
\end{abstract}

Kata kunci: Bencana, Digital Video Broadcasting, Sistem Peringatan Dini Bencana.

\section{PENDAHULUAN}

Dilihat secara geografis posisi Indonesia berada pada pertemuan 3 lempeng utama, yaitu Sirkum Mediterania (Alpide Belt), Sirkum Pasifik (Ring of Fire), dan Lempeng Australia yang menyebabkan Indonesia rawan terjadi gempa bumi. Di sisi lain Indonesia rentan terhadap bencana gunung meletus, lahar, dan awan panas. Hal ini disebabkan terdapat 129 gunung berapi aktif di Indonesia dimana 70 diantara meletus dalam 400 tahun terakhir. Gunung berapi tersebut tersebar secara merata di pulau-pulau di Indonesia terkecuali di wilayah Kalimantan. Sistem Peringatan Dini Bencana Alam atau Emergency Warning System (EWS) merupakan mekanisme pemberitahuan pesan sesegera mungkin sebelum terjadinya kemungkinan bencana alam pada suatu lokasi tertentu. Tujuan utama dari Emergency Warning System yaitu untuk meminimalisir jumlah korban. Dalam fungsinya, EWS sangat diperlukan pada kondisi wilayah rawan bencana misalnya di Indonesia. Dari beberapa hal tersebut, maka EWS di Indonesia diperlukan untuk meminimalisir dampak bencana. Terdapat beberapa solusi untuk membangun sistem peringatan dini bencana, salah satunya yaitu dengan membangun alarm-alarm pada daerah rawan bencana. Namun hal ini menggunakan biaya yang tidak sedikit. Disamping itu, lokasi Indonesia yang tersebar pada pulau-pulau serta luasnya wilayah Indonesia membuat pembangunan alarm-alarm pada wilayah potensi bencana menjadi sangat tidak efektif. Cara lain cara dalam membangun sistem peringatan dini bencana yaitu dengan menggunakan broadcast SMS. Pada satu sisi, teledensitas (penetrasi telepon seluler) di Indonesia yang melebihi 50\% dari jumlah penduduk sehingga pesan mudah dijangkau oleh penduduk, namun di sisi lain, infrastruktur BTS untuk transmisi SMS belum seluruhnya mencapai pelosok Indonesia. Selain 2 itu, biaya dalam transmisi SMS dalam implementasi untuk penanganan bencana ini dinilai cukup besar. Pada siaran televisi Analog menggunakan teknologi teleteks. Teleteks adalah sistem penyampaian informasi satu arah yang sistem pemancarannya dengan memanfaatkan garis televisi yang tidak dimanfaatkan dalam pengiriman sinyal gambar dan sinyal suara. Sinyal-sinyal teleteks ini ditumpangkan pada sinyal gambar televisi dalam bentuk digital, memproses informasi tersebut dan menampilkannya secara grafis di atas layar. 
Biasanya dapat ditampilkan pada saluran 888 atau 777. Sedangkan pada siaran TV Digital terdapat konvergensi yakni adanya penggabungan antara Gambar, Suara dan Data, data dapat dimasukan informasi tentang bencana. Hal ini yang menjadi alasan pengiriman sinyal EWS dikirim melalui siaran TV Digital, Salah satu solusi yang feasible dalam hal ini yaitu dengan menumpang pada jaringan televisi. Dengan ditetapkannya Peraturan Menteri Komunikasi dan Informatika Republik Indonesia No.07/P/M.KOMINFO/3/2007 tentang Penetapan Standar Penyiaran Digital Terrestrial untuk Telivisi Tidak Bergerak di Indonesia serta Peraturan Menteri Komunikasi dan Informatika Republik Indonesia No.39 Per/M.Kominfo/10/2009 Tentang Kerangka Dasar Penyelenggaraan Penyiaran Televisi Digitat Terestrial Penerimaan Tetap Tidak Berbayar (Free To Air) maka Indonesia secara resmi menggunakan standard siaran DVB-T sebagai standar penyiaran berbasis TV. Dalam roadmapnya disebutkan bahwa "alat bantu penerima siaran TV Digital (Set-Top-Box) dan perangkat penerima TV Digital standar harus memenuhi ketentuan teknis yang ditetapkan oleh pemerintah dengan fitur yang mampu memberikan layanan data dengan menu Bahasa Indonesia, peringatan dini bencana alam, dan dapat dilengkapi dengan sarana pengukuran rating TV". Dalam proses migrasi TV Digital sampai dengan tahun 2018 tersebut dan mengacu pada Buku Putih Penyiaran TV Digital di Indonesia bahwa dari 3 fitur yang harus dipenuhi salah satunya adalah perngatan dini bencana alam (Emergency Warning System). Namun dalam perkembangannya sampai sekarang, EWS yang disebutkan dalam regulasi belum ada yang 3 melakukan penelitian bagaimana arsitektur aliran pesan sistem peringatan dini (EWS) ini di Indonesia. Dengan adanya spesifikasi teknis ini dapat meningkatkan percepatan pendistribusian informasi peringatan dini bencana ke masyarakat.

\section{Tujuan dan Manfaat Penelitian}

Tujuan dari penelitian ini adalah untuk memperoleh analisa Aliran Data Sistem Peringatan Dini Bencana berbasis Siaran TV Digital, menganalisa dan mengembangkan Spesifikasi Teknis software pengiriman EWS, pengembangan Prototipe software pengiriman EWS pada multiplekser tv digital

Manfaat dilakukan penelitian ini adalah sebagai berikut.
1. Regulator dalam menentukan aturan dan kebijakan implementasi siaran tv digital.

2. Industri broadcast dalam melakukan investasi pengadaan perangkat

3. Masyarakat dalam mengetahui dengan cepat terjadinya bencana..

\section{LANDASAN TEORI}

\subsection{Siaran Televisi Digital}

Siaran televisi analog menggunakan 1 slot kanal frekuensi untuk 1 jenis siaran televisi. Selain itu, siaran televisi analog mewajibkan jeda 1 slot kanal sebagai guard band agar tidak terjadi interferensi. Dengan kata lain, siaran televisi analog setidaknya membutuhkan 2 slot kanal frekuensi agar siaran dapat berjalan dengan baik. Dengan adanya hal tersebut, terdapat pemborosan frekuensi pada siaran analog, padahal pada satu sisi, permintaan terhadap frekuensi untuk kebutuhan penyiaran selalu tumbuh, namun di sisi lain, frekuensi merupakan sumberdaya yang bersifat terbatas keberadaannya Dengan adanya fenomena tersebut, maka muncullah konsep siaran TV digital.

\subsection{Multiplexer TV Digital}

Format MPEG yang dipilih dalam standar siaran DVB adalah MPEGTransport Stream dikarenakan sifatnya yang Data Loss Tolerance(ISO/IEC 13818-1 1996]102). Dalam mentransmisikan konten, terdapat 4 tahapan /layer yang dilalui konten sebagaimana yang ditunjukkan pada Gambar I. Pada Gambar I tersebut secara proses detail yang terjadi yaitu:

1. Pada proses MPEG Compression Layer, dihasilkan Access Unit dari Presentation Unit yang berupa Video,Audio,atau Data kemudian di encode menjadi Elementary Stream (ES).

2. Elementary Stream dipecah menjadi paketpaket kecil menjadi Packetize Elementary Stream (PES)

3. PES di muxing untuk menghasilkan Program Stream atau Transport Stream (dalam DVB dipakai Transport Stream), kemudian ditambahkan informasi tambahan berupa Program Specific Information serta menambahkan system time agar lyphsinc antara audio, video dan data sempurna. Tugas Multiplex adalah untuk melakukan multiplexing PaketPaket MPEG menjadi Transport Stream.

4. Transport Stream di transmisikan melalui modulator dengan spesifikasi media 
tertentu (DVB-T, DVB-S, DVB-H atau DVB-C).

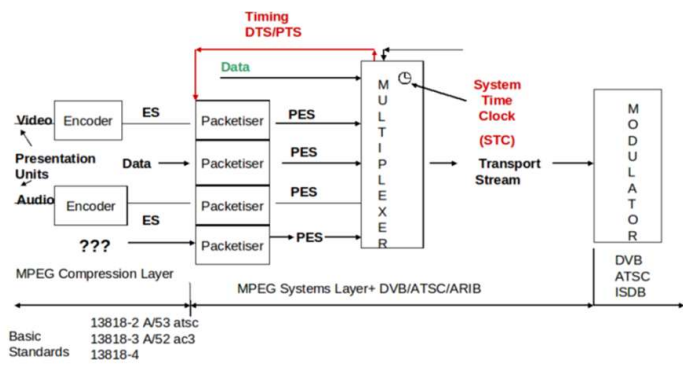

Gambar 1. Skema Layer Transmisi Konten Siaran TV Digital .

\subsection{Disaster Emergency Warning System}

Dengan melihat Disaster Emergency Warning System yang terdapat pada beberapa standar siaran TV di dunia, thesis ini mengusulkan aspek non-teknis dan aspek nonteknis Disaster Emergency Warning System di Indonesai. Adapun aspek non-teknis meliputi bagaimana tata keorganisasian, separation of duty atau batasan kewenangan masing-masing organisasi dan alur informasi bencana. Untuk aspek teknis meliputi meliputi spesifikasi teknis pemancar dan spesifikasi teknis penerima untuk standar peringatan dini bencana di Indonesia.

\subsection{Pola Pikir Pemecahan Masalah}

Pola pikir yang digunakan untuk memecahkan masalah pada penelitian ini dapat dilihat pada gambar sebagai berikut.

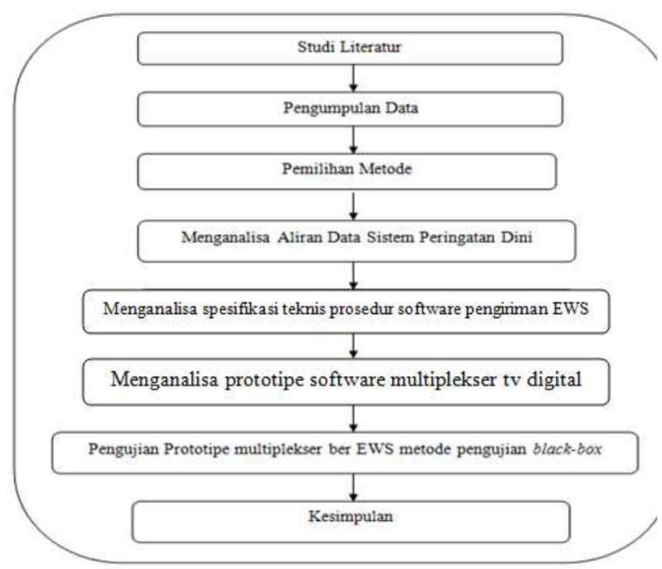

Gambar 2. Pola Pikir Pemecahan Masalah

Dari gambar di atas dapat dilihat pola pikir pemecahan masalah yang digunakan dalam penelitian ini. Hal itu dapat diuraikan sebagai berikut.

1) Studi Literatur objek penelitian.
2) Pengumpulan data penelitian.

3) Pemilihan Metoe, dalam hal ini adalah klasifikasi.

4) Menganaisa aliran data sistem, analisa yang akan dibandingkan adalah aliran data stream multiplekser pada tv digital

5) Analisis spesifikasi prosedur software pengiriman EWS.

6) Evaluation, rule yang dihasilkan dari kedua algoritma dilakukan dicoba dengan data testing untuk memvalidasinya.

\subsection{Hipotesis}

Hepotesis yang dibuat untuk penelitian ini adalah sebagai berikut.

Diduga spesifikasi teknis software pengiriman EWS \& prototipe software multiplekser tv digital dengan metode pengujian black-box testing dapat meningkatkan percepatan pendistribusian informasi peringatan dini bencana ke masyarakat.

\section{DESAIN PENELITIAN 4.1 Metode Penelitian}

Penelitian Pengembangan spesifikasi teknis prosedur software pengiriman EWS \& prototipe software multiplekser tv digital untuk sistem peringatan dini bencana (ews) di indonesia yang dilakukan merupakan jenis PenelitianTerapan (Applied Research). Hasil penelitian dapat langsung diterapkan untuk memecahkan permasalahan yang dihadapi.

\subsection{Metode Pengumpulan Data}

Data yang digunakan dalam penelitian ini adalah data sekunder. Data diperoleh dari objek penelitian, yaitu Kantor Pusat Teknologi Informasi dan Komunikasi di Badan Pengkajian dan Penerapan Teknologi. Parameter input sejumlah lima buah. Sedangkan parameter output-nya adalah satu buah. Hal itu dapat dilihat pada tabel di berikut ini.

Metode yang digunakan dalam pengumpulan data adalah

1) Studi dokumentasi, dilakukan dengan mengambil data dari sumber yang sudah ada di Kantor Pusat Teknologi Informasi dan Komunikasi BPPT;

2) Studi literatur, dilakukan dengan cara melakukan pencarian jurnal, artikel, $e$ books, dan literatur yang membahas Siaran Tv Digital terutama mengenai siaran multiplekser dan pengiriman data EWS. 


\subsection{Teknik Analisis dan Pengujian Sistem}

Teknik analisis yang digunakan pada penelitian ini adalah menggunakan pendekatan Object Oriented Analysis (OOA)atau analisis berorientasi obyek. Analisis dokumen sistem yang sudah berjalan. Analisis kebutuhan terhadap hasil

wawancara dengan pihak-pihak yang terkait. Analisis terhadap data yang telah dikumpulkan hasil olah dokumen dan lain-lain.

Pada prosesanalisis, terdapat empat macam analisis yang dilakukan yaitu:

1. Analisis sistem yang berjalan saat ini.

2. Analisis Kebutuhan Teknis dan NonTeknis.

3. Analisis Pengguna.

4. Analisis Perilaku Sistem. Pada tahapan ini, dilakukan analisis perilaku sistem yang dikembangkan dan dimodelkan dengan diagram skema pemancar siaran TV digital ber EWS.

\subsection{Langkah-langkah Penelitian}

Langkah-langkah yang dilakukan pada penelitian ini akan diuraikan sebagai berikut.

1. Identifikasi Masalah Identifikasi masalah mencakup tujuan dan ruanglingkup kegiatan serta hasil yang diharapkan.

\section{Studi Literatur}

Studi literatur mencakup pendalaman masalah yaitu bagaimana Standar DVB-T, bagaimana regulasi penyiaran TV Digital di Indonesia serta bagaimana Arsitektur, Implementasi EWS di negara lain dan Bagaimana spesifikasi teknis prosedur software pengiriman EWS siaran TV Digital ini dapat meningkatkan efisiensi pendistribusian informasi peringatan dini bencana ke masyarakat.

3. Perancangan Arsitektur Sistem

Perancangan meliputi kebutuhan sistem, alur sistem, blok diagram serta syntax coding pada pemancar siaran tv digital.

4. Implementasi Implementasi dilakukan untuk mendukung hasil perancangan arsitektur serta standar sistem.

5. Uji Coba dan Analisis Hasil Percobaan

Uji coba dilakukan pada skala lab dan maksimum pada siaran lokal dengan range tertentu.

\section{ANALISIS, INTERPRETASI DAN IMPLIKASI PENELITIAN}

\subsection{Data EWS}

ITU (International Telecommunication Union) dalam rekomendasi BT.1774-1 tentang Use of Satellite and Terrestrial Broadcast Infrastructures for Public Warning, Disaster Mitigation and Relief merekomendasikan konsep EWS untuk beberapa hal yaitu:

1. Dalam penyiaran digital konten EWS ditumpangkan pada jaringan multiplexing siaran, sehingga dapat secara otomatis mengaktifkan receiver yang dilengkapi dengan fiture EWS ketika dalam posisi stand-by.

2. Sinyal kontrol EWS harus dapat menerima fitur ini dalam kondisi apapun (robust).

3. Direkomendasikan fungsi receiver terdapat pada alat mobile seperti telepon selular sehingga lebih efektif dalam mengirim informasi darurat. Rekomendasi ITU diatas bersifat netral teknologi (tidak merujuk ke salah satu teknologi tertentu), namun ITU memberikan beberapa contoh penerapan EWS yang dinilai berhasil yaitu Jepang yang sejak tahun 1985 sukses mengimplementasi EWS untuk siaran analog, dan siaran digital ISDB yang difungsikan untuk mobile receiver dan terestrial pada tahun 2006; serta Korea yang mengimplementasikan EWS sejak tahun 2006 untuk siaran digital berbasis DMB.

\subsection{Analisis Pengguna}

Pada alur peran DEWS, input data bencana berdasarkan dari sinyal sensor, sementara Emergency Agency berperan untuk mengolah bencana menjadi format RSS, sementara DEWS Broadcaster berperan dalam mengkonversi informasi dari Emergency Agency ke bentuk Transport Stream. Pesan dari Emergency Agency yang berbentuk Transport Stream tersebut disebarkan melalui internet dengan menggunakan teknik UDP. Tranport Stream yang diterima dimultipleks dengan konten program yang ada kemudian disebarkan oleh multiplexer dengan bantuan 26 pemancar atau transmitter. Di sisi pengguna, set-top-box berfungsi untuk memfilter pesan yang disampaikan informasinya ke pengguna. 


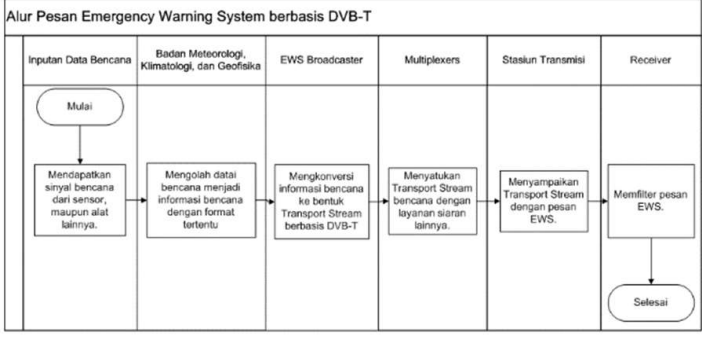

Gambar 3 Alur Peran Usulan Sistem Peringatan Dini Bencana [PTIK-BPPT 2011]

\subsection{Analisis Perilaku Sistem}

Skema Sistem Peringatan Dini Bencana Alam dapat dilihat pada Gambar IV-2. Sensor bencana mengirimkan deteksinya terhadap potensi bencana ke Server Bencana. Dari Server Bencana, pesan akan dibroadcast ke semua Multiplexer. Pesan tersebut memiliki pairingcode yaitu berupa Transport Stream ID yang merupakan kode unik multiplexer. Pesan kemudian diteruskan ke Set-Top-Box pengguna atau TV Digital yang telah dilengkapi dengan fitur Peringatan Dini Bencana. Set-Top-Box akan melakukan pairing, jika Transport Stream ID yang dikirim Server Benana adalah sama dengan Transport Stream Multiplexer maka pesan akan berbunyi (display on TV).

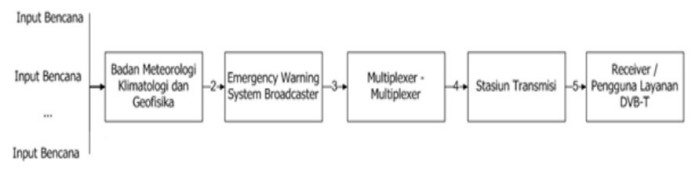

Gambar 4. Skema Usulan Sistem Peringatan Dini Bencana [PTIK-BPPT 2011]

\subsection{Pembuatan Graphical User Interface (GUI)}

Dengan menggunakan Aplikasi prototype pada Server Bencana dibuat dengan Java yang berjalan pada Linux Based Operating System. Tampilan implementasi. aplikasi server bencana terdiri dari 4 fungsi utama yaitu:

1. Textbox untuk menambahkan lokasi URL Server Emergency Agency berdasarkan jenis-jenis bencana yang ada pada ComboBox.

2. List Grid menampilkan URL bencana. Aplikasi perperiode akan mengupdate pesan bencana yang bersumber dari URL di List Grid ini.

3. Broadcast IP beserta Port yang wajib dilisten oleh Multiplexer Server beserta Portnya.
4. NetworkID yang dimiliki oleh server bencana. Network ID bertujuan mengetahui/men-tracing sumber informasi dimana pesan bencana dimunculkan.

5. Tombol "Start Server" untuk memulai monitor bencana.

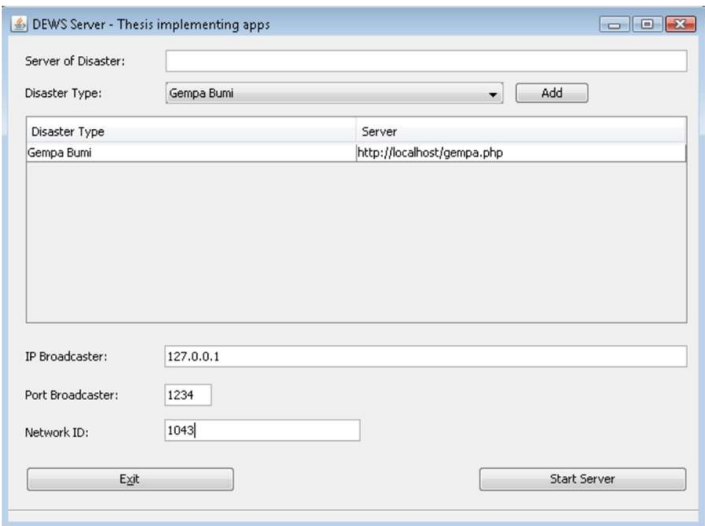

Gambar 4. GUI Aplikasi prototype pada Server Bencana

\subsection{Implementasi Pengujian}

Proses pengujian sistem dilakukan dengan metode pengujian blackbox testing. Proses pengujian hanya memperhatikan masukan dan keluaran yang ada pada sistem, tidak memperhatikan baris-baris program, algoritmaalgoritma, dan sebagainya. Pengujian dilakukan dengan memberikan sejumlah masukan yang mungkin diberikan pengguna kemudian melihat keluaran yang dihasilkan sistem apakah berjalan dengan benar dan sesuai dengan kebutuhan fungsional

\section{PENUTUP \\ 6.1 Simpulan}

Dengan adanya arsitektur aliran pesan sistem peringatan dini (EWS) mampu menyebarkan pesan bencana secara terlokalisir. Arsitektur aliran pesan EWS adalah sebagai berikut :

1. Badan Meterologi, Klimatologi dan Geofisika mendapat input bencana berupa sensor, input data berupa raw data,

2. Bentuk raw data disusun menjadi informasi yang diberikan ke pemancar EWS,

3. Pemancar EWS mengirimkan format bencana dalam bentuk transport stream ke multiplekser,

4. Multiplekser melakukan multipleksing pesan bencana dengan servis lainnya, dan siap di transmisikan, 
5. Transmiter melakukan transmisi konten dalam bentuk DVB-T yang telah ada pesan EWS,

6. Pesan EWS diterima receiver untuk diolah, apakah terdapat sinyal, EWS untuk lokasi tersebut atau tidak.

\subsection{Saran}

Adapun saran pengembangan yang diusulkan oleh penulis berkaitan dengan penelitian yang telah dilakukan adalah:

1. Menginventarisi list daftar multiplekser agar titik-titik bencana dapat tercoverage secara sempurna.

2. Membuat sistem cerdas untuk menentukan multiplekser mana yang ditunjuk untuk menyebarkan pesan bencana.

\section{DAFTAR PUSTAKA}

[1] Budiarto, H. Menuju Implementasi Siaran Televisi Digital Terrestial di Indonesia, Paper e-Indonesia Initiative, 2007.

[2] ETSI EN $300 \quad 744$ Digital Video Broadcasting(DVB). Framing Structure, channel Coding and Modulation for Digital Terestrial Television, volume v.1.5.1, 2004.

[3] Kwon, S.-G., Jun, H., Lee, S.-H., \& Kwon, K.R. (2009). TII Based T-DMB Location AEAS Receiver Model. IEEE, 2009..

[4] Nagaosa Y, ISDB-T Transmission Technology Single transmission for fixed, vehicular and handheld receivers, International ICT Summit, Uzbekistan, 2008.

[5] Pressman, S, Roger. Software Engineering: A Practitioner's Approach, 7th ed. Penerj. Adi Nugroho, J, Leopold Nikijuluw George dan et.al. Yogyakarta: ANDI, 2012. 